\title{
The -1154 G/A VEGF gene polymorphism is associated with the incidence of basal cell carcinoma in patients from northern Poland
}

\author{
Michał Sobjanek • Monika Zabłotna • Aleksandra Lesiak • Igor Michajłowski • \\ Aneta Szczerkowska-Dobosz • Małgorzata Sokolowska-Wojdylo • \\ Roman Nowicki
}

Received: 23 November 2013/Revised: 10 April 2014/ Accepted: 1 May 2014/Published online: 6 June 2014 (C) The Author(s) 2014. This article is published with open access at Springerlink.com

\begin{abstract}
Vascular endothelial growth factor (VEGF) is believed to play a crucial role in neoplastic angiogenesis. Although the genetic background of basal cell carcinoma (BCC) has been analyzed in some papers, the mechanism of BCC pathogenesis is not fully understood. To the best of our knowledge, VEGF gene polymorphisms have not yet been explored. The aim of the study was to asses the frequency of three polymorphisms in the VEGF gene $(-1154$ G/A, -460 T/C and $+405 \mathrm{G} / \mathrm{C}$ ) in patients of Polish origin with $\mathrm{BCC}$ and control group. In addition, VEGF serum levels of patients with BCC and controls were measured. The study involved 180 patients ( 96 women, 84 men) with BCC and a mean age of $68.9 \pm 11.8$, and 215 healthy ageand sex-matched volunteers. The VEGF polymorphisms at positions -1154 and +405 were analyzed using the amplification refractory mutation system polymerase chain reaction method. To assess the VEGF gene polymorphism at position -460 , we used the polymerase chain reaction restriction fragment length polymorphism method. Serum levels of VEGF protein were measured using the ELISA test. The presence of the G allele (GA or GG) in the -1154 $V E G F$ polymorphism was associated with an increased risk of BCC development (OR $=7.28, p<0.0001)$. Furthermore, the carriers of the AA genotype in -1154 VEGF
\end{abstract}

M. Sobjanek $(\bowtie) \cdot$ M. Zabłotna · I. Michajłowski .

A. Szczerkowska-Dobosz · M. Sokolowska-Wojdylo ·

R. Nowicki

Department of Dermatology, Venereology and Allergology,

Medical University of Gdańsk, ul. Debinki 7, 80-952 Gdańsk,

Poland

e-mail:sobjanek@wp.pl

A. Lesiak

Department of Dermatology and Venereology, Medical

University of Łódź, Łódź, Poland polymorphism showed significantly reduced risks of BCC $(\mathrm{OR}=0.14, p<0.0001)$. It was also shown that the GTC haplotype of $V E G F$ predisposes to BCC development $(\mathrm{OR}=1.69, p=0.013)$, while the presence of the ATG haplotype significantly reduces this risk $(\mathrm{OR}=0.17$, $p=0.00001)$. We have found significantly increased VEGF serum levels among BCC patients, in comparison with the healthy controls (mean $596.7 \pm 393.5 \mathrm{pg} / \mathrm{ml}$; range $60.1-931.4$ vs. $255.9 \pm 174.6 \mathrm{pg} / \mathrm{ml} ; \quad$ range $42.2-553.0 \mathrm{pg} / \mathrm{ml} ; p<0.0004)$. The serum levels of VEGF significantly correlated with tumor size: $r=0.41$, $p<0.0001$. Our results testify to the importance of -1154 G/A VEGF gene polymorphisms in altering the risk of BCC among the population from northern Poland.

Keywords Basal cell carcinoma - VEGF - Vascular endothelial growth factor $\cdot$ Gene $\cdot$ Polymorphism

\section{Introduction}

Angiogenesis plays the main role in local tumor growth and invasion, as well as in metastasis. It is known that, without the formation of new vessels, tumors cannot exceed 1-2 $\mathrm{mm}$ in diameter [2-4].

Vascular endothelial growth factor (VEGF) is believed to play a crucial role in neoplastic angiogenesis. VEGF overexpression and elevated serum levels of this cytokine have been observed in several malignancies [2].

The VEGF gene is located on chromosome 6 (6p12.1) and is highly polymorphic. The $-1154 \mathrm{G} / \mathrm{A},-460 \mathrm{~T} / \mathrm{C}$, and $+405 \mathrm{G} / \mathrm{C}$ VEGF polymorphisms have been reported as functionally relevant and associated with an increased risk of development of various inflammatory or neoplastic processes $[16,26]$. 
The pathogenesis of basal cell carcinoma (BCC) - the most common malignancy in Caucasian populations is complex, but is strongly associated with environmental and genetic factors. Although the genetic background of BCC has been analyzed in some research, the mechanism of BCC pathogenesis is not yet fully understood. To the best of our knowledge, $V E G F$ gene polymorphisms have not been explored to date in this context [12].

In this study, three polymorphisms in the $V E G F$ gene ($1154 \mathrm{G} / \mathrm{A},-460 \mathrm{~T} / \mathrm{C}$, and $+405 \mathrm{G} / \mathrm{C}$ ) were assessed in relation to the risk of $\mathrm{BCC}$ incidence in a population from northern Poland and some clinical aspects of the malignancy. In addition, VEGF serum levels of patients with BCC were compared with those of a control population.

\section{Materials and methods}

Patients and controls

The study included 180 unrelated patients with BCC and of mean age $68.9 \pm 11.8$ (96 women, 84 men) and 215 healthy, unrelated age- and sex-matched volunteers (Table 1). None of the subjects were organ transplant recipients, none were being treated with immunosuppressive drugs, and none suffered from any systemic inflammatory disease or malignancy. All subjects were exclusively of Eastern European/Polish descent.

The study was approved by the local research ethics committee of the Medical University of Gdańsk.

Table 1 Characteristics of the BCC patients investigated

\begin{tabular}{llll}
\hline & Males & Females & $\begin{array}{l}\text { Overall } \\
\text { group }\end{array}$ \\
\hline & $84(46.7 \%)$ & $96(53.3 \%)$ & 180 \\
Age (mean \pm SD) & $69.6 \pm 9.9$ & $68.5 \pm 13.1$ & $68.9 \pm 11.8$ \\
$<60$ years & $13(37.1 \%)$ & $22(62.9 \%)$ & $35(22.6 \%)$ \\
$>60$ years & $59(49.2 \%)$ & $61(50.8 \%)$ & $120(77.4 \%)$ \\
Tumor size $(\mathrm{cm})$ & & & \\
$\leq 1$ & $27(35.1 \%)$ & $50(64.9 \%)$ & $77(48.4 \%)$ \\
$>1$ & $44(53.7 \%)$ & $38(46.3 \%)$ & $82(51.6 \%)$ \\
Recognition: & & & \\
BCC & $71(45.8 \%)$ & $84(54.2 \%)$ & $155(90.6 \%)$ \\
BCC recurrence & $7(43.7 \%)$ & $9(56.2 \%)$ & $16(9.4 \%)$ \\
Number of tumors: & & & \\
One tumor & $62(43.1 \%)$ & $82(56.9 \%)$ & $144(81.8 \%)$ \\
Multiple tumors & $19(59.4 \%)$ & $13(40.6 \%)$ & $32(18.2 \%)$ \\
Location: & & & \\
Area exposed to UV & $58(42.6 \%)$ & $78(57.4 \%)$ & $136(85.0 \%)$ \\
Area not exposed to & $14(58.3 \%)$ & $10(41.7 \%)$ & $24(15.0 \%)$ \\
$\quad$ UV & & & \\
\hline
\end{tabular}

Patients with BCC were subclassified by tumor site, tumor size, age, and recurrence.

\section{VEGF genotyping}

The VEGF polymorphisms at positions -1154 and +405 were analyzed using the amplification refractory mutation system polymerase chain reaction method (ARMS-PCR), as has been described in [7].

To assess VEGF gene polymorphisms at position -460 , we employed the polymerase chain reaction restriction fragment length polymorphism method (PCR-RFLP) according to the method described by Kuo et al. [11].

VEGF serum level analysis

Serum concentrations of VEGF were measured in 135 patients with BCC and in 62 unaffected subjects. The median values for the protein concentration were not affected by the age or sex at enrollment in either the BCC cases or the controls.

Serum levels of VEGF protein were measured using the ELISA test (The Quantikine Human VEGF Immunoassay, R\&D Systems, Inc., Minneapolis, USA), following the manufacturer's instructions.

Statistical analysis

The $\chi^{2}$ analysis was used to compare the observed number of genotypes with that expected for a population in a Hardy-Weinberg equilibrium. The $\chi^{2}$ analysis was also employed to test the significance of the differences in the observed alleles and genotypes between groups. A logistic regression model was used to calculate the odds ratios (ORs) and the $95 \%$ confidence intervals (CIs). The MannWhitney $U$ test was used to compare the mean values, and the correlation was determined using mean Spearman coefficient values. Analyses were performed using the Statistica 8.0 software package (StatSoft, Inc., 2008). $p<0.05$ was considered statistically significant. Haplotype estimation was carried out using the Phase v2.1 software package.

\section{Results}

Analysis of VEGF polymorphism

The distribution of the $V E G F$ genotypes was consistent with a Hardy-Weinberg equilibrium only in the control group.

The VEGF genotype frequency of each of the groups is shown in Table 2. 
Table 2 Genotypes and alleles frequencies for VEGF $-1154 \mathrm{G} / \mathrm{A},-460 \mathrm{~T} / \mathrm{C}$ and $+405 \mathrm{G} / \mathrm{C}$ in patients with BCC and control subjects

\begin{tabular}{|c|c|c|c|c|}
\hline $\begin{array}{l}\text { Genotypes and } \\
\text { alleles }\end{array}$ & Controls & $\mathrm{BCC}$ & OR $(95 \% \mathrm{CI}), p$ & aOR $(95 \% \mathrm{CI}), p$ \\
\hline-1154 & $n=215$ & $n=180$ & & \\
\hline GG & $75(34.9 \%)$ & $64(35.6 \%)$ & NS & NS \\
\hline GA & $103(47.9 \%)$ & $111(61.7 \%)$ & $\begin{array}{l}1.75(1.27-2.89) \\
p=\mathbf{0 . 0 0 6}\end{array}$ & $\begin{array}{c}1.87(1.75-1.99) \\
p<\mathbf{0 . 0 0 0 0 1}\end{array}$ \\
\hline AA & $37(17.2 \%)$ & $5(2.8 \%)$ & $\begin{array}{c}\mathbf{0 . 1 4}(0.04-0.32) \\
p<\mathbf{0 . 0 0 0 1}\end{array}$ & $\begin{array}{c}\mathbf{0 . 0 9}(0.08-0.11) \\
p<\mathbf{0 . 0 0 0 0 1}\end{array}$ \\
\hline \multirow[t]{2}{*}{$\mathrm{GG}+\mathrm{GA}$ vs AA } & $178(82.8 \%)$ vs. $37(17.2 \%)$ & $175(97.2 \%)$ vs. $5(2.8 \%)$ & $\begin{array}{c}7.28(3.07-25.40) \\
p<\mathbf{0 . 0 0 0 1}\end{array}$ & $\begin{array}{c}\mathbf{1 0 . 5 2}(9.02-12.27), \\
p<\mathbf{0 . 0 0 0 0 1}\end{array}$ \\
\hline & $n=430$ & $n=360$ & & \\
\hline G & $253(58.8 \%)$ & $239(66.4 \%)$ & $p=\mathbf{0 . 0 3} *$ & $p=\mathbf{0 . 0 3} *$ \\
\hline A & $177(41.2 \%)$ & $121(33.6 \%)$ & & \\
\hline-460 & $n=215$ & $n=180$ & & \\
\hline TT & $59(27.4 \%)$ & $42(23.3 \%)$ & NS & NS \\
\hline $\mathrm{TC}$ & $119(55.3 \%)$ & $110(61.1 \%)$ & NS & NS \\
\hline \multirow[t]{2}{*}{$\mathrm{CC}$} & $37(17.21 \%)$ & $28(15.6 \%)$ & NS & NS \\
\hline & $n=430$ & $n=360$ & & \\
\hline $\mathrm{T}$ & $237(55.1 \%)$ & $194(53.9 \%)$ & NS & NS \\
\hline $\mathrm{C}$ & $193(44.9 \%)$ & $166(46.1 \%)$ & NS & NS \\
\hline+405 & $n=215$ & $n=180$ & & \\
\hline GG & $123(57.2 \%)$ & $90(50.0 \%)$ & NS & NS \\
\hline GC & $86(40.0 \%)$ & $85(47.2 \%)$ & NS & NS \\
\hline \multirow[t]{2}{*}{$\mathrm{CC}$} & $6(2.8 \%)$ & $5(2.8 \%)$ & NS & NS \\
\hline & $n=430$ & $n=360$ & & \\
\hline G & $332(77.2 \%)$ & $265(73.6 \%)$ & NS & NS \\
\hline $\mathrm{C}$ & $98(22.8 \%)$ & $95(26.4 \%)$ & NS & NS \\
\hline
\end{tabular}

Bold values are statistically significant $(p<0.05)$

$B C C$ basal cell carcinoma, $O R$ crude odds ratio, $a O R$ adjusted odds ratio, $C I$ confidence interval, $N S$ not significant

* $\chi^{2}$ Pearsona

Table 3 Haplotype frequencies for VEGF -1154 G/A, -460 T/C and +405 G/C estimated using PHASE version 2.1

\begin{tabular}{lcrll}
\hline Haplotype $-1154,-460,+405$ & Controls $(n=430)$ & BCC $(n=360)$ & OR $(0.95 \%$ CI $), p$ & aOR (95 \%CI), $p$ \\
\hline ACG & $114(26.5 \%)$ & $101(28.1 \%)$ & NS & NS \\
GCG & $71(16.5 \%)$ & $62(17.2 \%)$ & NS & NS \\
GTG & $108(25.1 \%)$ & $97(26.9 \%)$ & NS & NS \\
ATG & $39(9.1 \%)$ & $6(1.7 \%)$ & $\mathbf{0 . 1 7}(0.07-0.40), p=\mathbf{0 . 0 0 0 0 1}$ & $\mathbf{0 . 2 1}(0.18-0.23), p<\mathbf{0 . 0 0 0 0 1}$ \\
GTC & $72(16.7 \%)$ & $80(22.2 \%)$ & $\mathbf{1 . 6 9}(1.09-2.47), p=\mathbf{0 . 0 1 3}$ & $\mathbf{1 . 8 8}(1.76-2.02), p<\mathbf{0 . 0 0 0 0 1}$ \\
ATC & $18(4.2 \%)$ & $11(3.1 \%)$ & NS & NS \\
ACC & $6(1.4 \%)$ & $3(0.8 \%)$ & NS & NS \\
GCC & $2(0.5 \%)$ & $0(0.0 \%)$ & NS & NS \\
\hline BC
\end{tabular}

Bold values are statistically significant $(p<0.05)$

Allele frequencies did not significantly differ across all BCC patients and controls at the -460 and +405 loci, but at position -1154 , the $\mathrm{G}$ allele was observed statistically more frequently among patients $(p=0.03)$.

The presence of the $\mathrm{G}$ allele (GA or GG) in -1154 VEGF polymorphism was associated with an increased risk of developing $\mathrm{BCC}(\mathrm{OR}=7.28, p<0.0001)$. Furthermore, the carriers of the AA genotype in -1154 VEGF polymorphism showed a significantly reduced risk of $\mathrm{BCC}(\mathrm{OR}=0.14$, $p<0.0001)$.

Haplotype frequencies for the $-1154 \mathrm{G} / \mathrm{A},-460 \mathrm{~T} / \mathrm{C}$, and $+405 \mathrm{G} / \mathrm{C}$ polymorphism of $V E G F$ are shown in 


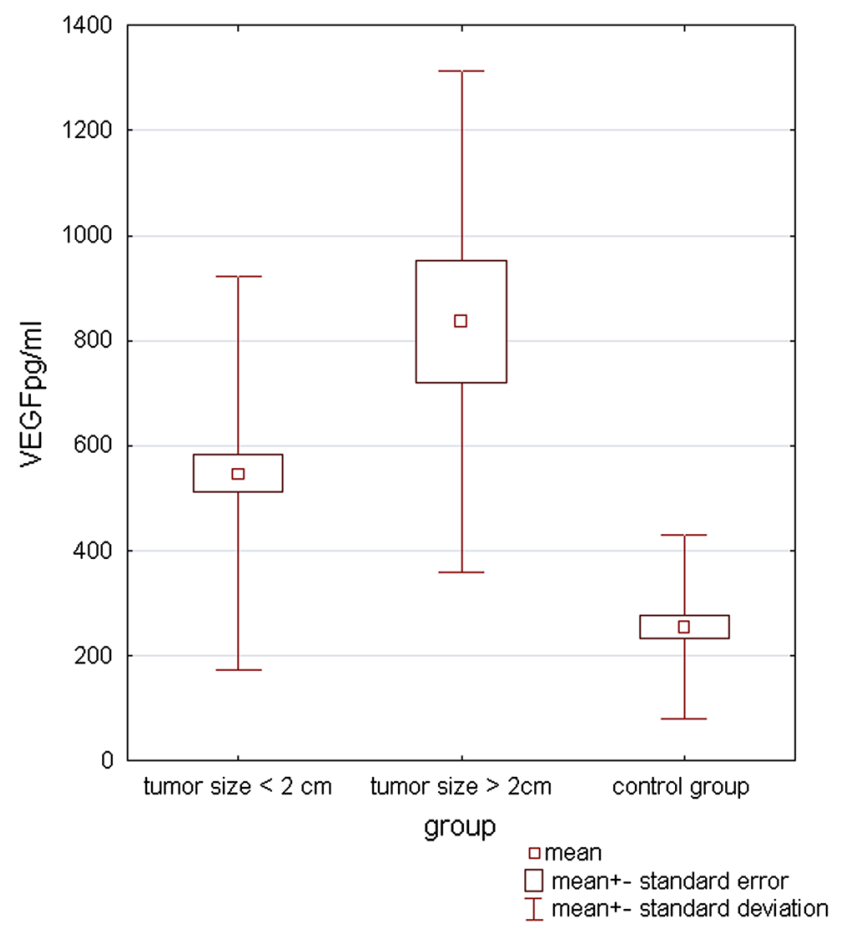

Fig. 1 Correlation of VEGF serum levels with tumor size $(\mathrm{cm})$

Table 3. These data demonstrate that the haplotype frequencies differ significantly between the BCC cases and the controls $(p=0.03)$.

It was shown that the GTC haplotype of VEGF predisposes to $\mathrm{BCC}$ development $(\mathrm{OR}=1.69, p=0.013)$, while the presence of the ATG haplotype significantly reduces that risk $(\mathrm{OR}=0.17, p=0.00001)$.

The higher frequency of the GG genotype in -1154 $V E G F$ polymorphisms was observed in patients with tumors localized on unexposed areas, as compared to those with tumors on exposed areas (45.8 vs. $33.1 \%)$ ). The A allele was observed more frequently in the case of BCC on sun-exposed skin (66.9 vs. $54.2 \%$ ).

Age analysis of the BCC patients shows a significantly higher occurrence of the GG genotype in patients older than 60 (40.8 vs. $11.4 \% ; p=0.001)$.

\section{VEGF serum level}

We found significantly increased VEGF serum levels among BCC patients, in comparison with healthy controls (mean $596.7 \pm 393.5 \mathrm{pg} / \mathrm{ml}$; range $60.1-931.4$ vs. $255.9 \pm 174.6 \mathrm{pg} / \mathrm{ml} ; \quad$ range $42.2-553.0 \mathrm{pg} / \mathrm{ml}$; $p<0.0004)$. Moreover, higher levels of VEGF were observed in patients with tumors localized on unexposed areas $(764.49 \pm 365.18$ vs. $559.98 \pm 397.66 ; p=0.023)$ and with size greater than $2 \mathrm{~cm}(836.1 \pm 476.9$ vs. $547.4 \pm 373.8 ; \quad p=0.0052$ ). Serum levels of VEGF significantly correlated with tumor size: $r=0.41$, $p<0.0001$ (Fig. 1).

There was no significant association between patients' ages and their VEGF serum levels. No correlations were demonstrated between the analyzed VEGF polymorphisms and the VEGF serum levels ( $p>0.05$ for all comparisons).

\section{Discussion}

Ultraviolet radiation plays a crucial role in the pathogenesis of skin cancers. However, the significant number of tumors that arise on areas of the skin that are not exposed to the sun suggests that other factors also play a role in the pathogenesis of BCC. An association between BCC development and personal and family history of skin cancer has been demonstrated [13].

Genetic studies in patients with BCC tend to focus on the genes involved in DNA repair, defense against oxidative stress and other mutagens, immune modulation, tanning, and other biochemical activities. To date, these studies have provided inconsistent results, perhaps indicating variability in the selection and numbers of patients and controls, or reflecting different effects in different cancers [10, 12, 22, 24].

Many potent angiogenic factors have been described in malignancies. Recent data strongly indicate that VEGF is the main protein involved in tumor growth and metastasis. Previous studies performed on a number of types of tumors (breast, oral, lung, colorectal, and prostate cancer) have demonstrated that this cytokine is overexpressed and that its enhanced level correlates with poor prognosis $[3,9,20$, 23, 26].

In many different types of malignancies, the $V E G F$ gene single nucleotide polymorphisms were associated with disease susceptibility, disease progression, and resistance to treatment $[1,6,8,11,14-16,25]$. The role of VEGF and its gene polymorphisms in non-melanoma skin cancers has not been studied so far.

This study has evaluated the potential impact of three $V E G F$ gene polymorphisms on the presence of $\mathrm{BCC}$ and on some of its clinical aspects. We have found only an association between $-1154 \mathrm{G} / \mathrm{A}$ VEGF polymorphism and BCC development. The presence of the $\mathrm{G}$ allele correlated with an eightfold higher risk of malignancy. The AA genotype was associated with a reduced risk of BCC. A similar observation was made by McCarron et al. [17], who demonstrated that the AA genotype in this polymorphism reduces the risk of prostate cancer (OR, 0.45). Li et al. [14] confirmed this phenomenon in an ovarian cancer cohort study. Our results suggest a potential protective effect of the AA genotype in the -1154 G/A VEGF polymorphism against $\mathrm{BCC}$ development. This finding is in accordance 
with the results of Howell et al. [6], who showed that the AA genotype is associated with a thinner primary vertical growth phase of cutaneous melanoma, in contrast to GG genotype carriers, who showed thicker tumors. Based on these data, it may be concluded that the presence of the AA genotype may be correlated with slower disease progression, probably thanks to its influence on the encoding of protein expression. However, many environmental factors may affect the regulation of gene expression.

We have also shown a higher frequency of the GG genotype in $-1154 \mathrm{G} / \mathrm{A}$ VEGF polymorphism in BCC cases that are localized on an unexposed area. This interesting observation might indicate, apart from UVR, the role of VEGF polymorphism in BCC pathogenesis.

The fact that GG genotype occurs more frequently in patients older than 60 is probably coincidental, and indicates that further investigation is required on a larger population.

In various cancers, a positive correlation was revealed between VEGF serum levels and tumor size, as well as between lymph node involvement and the presence of metastases [26].

We have also found higher VEGF serum levels in BCC patients, compared with the controls. Moreover, a positive association between VEGF serum levels and tumor size and site was found which may underline the role of VEGF in tumor aggressiveness. In some reports, the impact of various $V E G F$ polymorphisms on cytokine synthesis was shown $[5,20]$. Although we have not found the analyzed polymorphisms to have a significant influence on cytokine serum concentrations in patients, we have demonstrated this relationship in controls, showing that the presence of the GG genotype -1154 in G/A VEGF polymorphisms is linked to higher VEGF serum concentrations. These results are consistent with some other reports [21, 29].

Recently, novel therapeutic strategies including antiVEGF agents (bevacizumab, aflibercept, regorafenib, and ramucirumab) have been introduced for metastatic renal cell carcinoma and for nonsquamous non-small-cell lung cancer, melanoma, glioblastoma, pancreatic cancer, and metastatic colorectal cancer [7, 19]. Our results support the thesis that VEGF may be a good indicator of disease severity and localization, and it is likely that topical therapies directed against VEGF or its receptors will constitute new approaches to BCC treatment.

Some studies have shown that ACE inhibitors can significantly inhibit tumor growth and angiogenesis in some malignancies, and suppress VEGF [27, 28]. Napoleone et al. [18] demonstrated that downregulation of renninangiotensin system by ACE inhibitors and angiotensin receptor blockers inhibits tissue factor and VEGF expression in highly metastatic breast cancer cells.
Yapijakis et al. [27] analyzed a functional polymorphism in the ACE gene, which affects its transcription, with risk for BCC. They showed that ACE polymorphism is associated with decreased risk for BCC in ID heterozygotes. That novel observation suggests that rennin-angiotensin system inhibition may be considered also as a new potential strategy for combined modalities in BCC treatment.

In conclusion, our results testify to the importance of $-1154 \mathrm{G} / \mathrm{A} V E G F$ gene polymorphisms in altering the risk of BCC within a population from northern Poland. The interactions that determine other VEGF polymorphisms, skin VEGF expression in tumors, solar UV exposure, and various environmental factors should be performed in future studies, to confirm the links between gene polymorphisms and $\mathrm{BCC}$ risk.

Acknowledgment The study was funded by the Medical University of Gdańsk, Project No. ST-66.

Ethical standard The study was approved by the local ethics committee of the Medical University of Gdańsk.

Open Access This article is distributed under the terms of the Creative Commons Attribution License which permits any use, distribution, and reproduction in any medium, provided the original author(s) and the source are credited.

\section{References}

1. Cheng D, Kong H, Li Y (2013) Prognostic values of VEGF and IL-8 in malignant pleural effusion in patients with lung cancer. Biomarkers 18:386-390

2. Ferrara N, Gerber HP, LeCouter J (2003) The biology of VEGF and its receptors. Nat Med 9:669-676

3. Foekens JA, Peters HA, Grebenchtchikov N et al (2001) High tumor levels of vascular endothelial growth factor predict poor response to systemic therapy in advanced breast cancer. Cancer Res 61:5407-5414

4. Folkman J (2002) Role of angiogenesis in tumor growth and metastasis. Semin Oncol 29:15-18

5. Folkman J (1971) Tumor angiogenesis: therapeutic implications. N Engl J Med 285:1182-1186

6. Howell WM, Bateman AC, Turner SJ, Collins A, Theaker JM (2002) Influence of vascular endothelial growth factor single nucleotide polymorphisms on tumour development in cutaneous malignant melanoma. Genes Immun 3:229-232

7. Hsu JY, Wakelee HA (2009) Monoclonal antibodies targeting vascular endothelial growth factor: current status and future challenges in cancer therapy. BioDrugs 23:289-304

8. Jain L, Vargo CA, Danesi R, Sissung TM, Price DK, Venzon D, Venitz J, Figg WD (2009) The role of vascular endothelial growth factor SNPs as predictive and prognostic markers for major solid tumors. Mol Cancer Ther 8:2496-2508

9. Klasa-Mazurkiewicz D, Jarząb M, Milczek T, Lipińska B, Emerich J (2011) Clinical significance of VEGFR-2 and VEGFR3 expression in ovarian cancer patients. Pol J Pathol 62:31-40

10. Kosiniak-Kamysz A, Pośpiech E, Wojas-Pelc A, Marcińska M, Branicki W (2012) Potential association of single nucleotide 
polymorphisms in pigmentation genes with the development of basal cell carcinoma. J Dermatol 39:693-698

11. Ku KT, Wan L, Peng HC, Tsai MH, Tsai CH, Tsai FJ (2005) Vascular endothelial growth factor gene $-460 \mathrm{C} / \mathrm{T}$ polymorphism is a biomarker for oral cancer. Oral Oncol 41:497-502

12. Lesiak A, Norval M, Wodz-Naskiewicz K, Pawliczak R, Rogowski-Tylman M, Sysa-Jedrzejowska A, Sobjanek M, Wlodarkiewicz A, Narbutt J (2011) An enhanced risk of basal cell carcinoma is associated with particular polymorphisms in the VDR and MTHFR genes. Exp Dermatol 20:800-804

13. Lesiak A, Slowik-Rylska M, Rogowski-Tylman M, Norval M, Narbutt J (2010) Risk factors in Central Poland for the development of superficial and nodular basal cell carcinomas. Arch Med Sci 6:270-275

14. Li Y, Wang Y, Kang S, Wang N, Zhou RM, Duan YN, Sun DL, Qin JJ, Zhao W, Zhao L (2010) Association of vascular endothelial growth factor gene polymorphisms with susceptibility to epithelial ovarian cancer. Int J Gynecol Cancer 20:717-723

15. Luo T, Chen L, He P, Hu QC, Zhong XR, Sun Y, Yang YF, Tian TL, Zheng H (2013) Vascular endothelial growth factor (VEGF) gene polymorphisms and breast cancer risk in a Chinese population. Asian Pac J Cancer Prev 14:2433-2437

16. Masago K, Fujita S, Kim YH, Hatachi Y, Fukuhara A, Nagai H, Irisa K, Ichikawa M, Mio T, Mishima M (2009) Effect of vascular endothelial growth factor polymorphisms on survival in advanced-stage non-small-cell lung cancer. Cancer Sci 100:1917-1922

17. McCarron SL, Edwards S, Evans PR, Gibbs R, Dearnaley DP, Dowe A, Southgate C, Easton DF, Eeles RA, Howell WM (2002) Influence of cytokine gene polymorphisms on the development of prostate cancer. Cancer Res 62:3369-3372

18. Napoleone E, Cutrone A, Cugino D, Amore C, Di Santo A, Iacoviello L, de Gaetano G, Donati MB, Lorenzet R (2012) Inhibition of the renin-angiotensin system downregulates tissue factor and vascular endothelial growth factor in human breast carcinoma cells. Thromb Res 2012:736-742

19. Saif MW (2013) Anti-VEGF agents in metastatic colorectal cancer (mCRC): are they all alike? Cancer Manag Res 11:103-115

20. Seo Y, Baba H, Fukuda T et al (2000) High expression of vascular endothelial growth factor is associated with liver metastasis and poor prognosis in ductal pancreatic adenocarcinoma. Cancer 88:2239-2245

21. Sivaprasad S, Govardhan B, Harithakrishna R, Venkat Rao G, Pradeep R, Kunal B, Ramakrishna N, Anuradha S, Reddy DN (2013) Association of vascular endothelial growth factor (VEGF) gene polymorphism and increased serum VEGF concentration with pancreatic adenocarcinoma. Pancreatology 13:267-272

22. Skov L, Allen MH, Bang B et al (2003) Basal cell carcinoma is associated with high TNF-alpha release but nor with TNF-alpha polymorphism at position -308. Exp Dermatol 12:772-776

23. Su JL, Yen CJ, Chen PS, Chuang SE, Hong CC et al (2007) The role of the VEGF-C/VEGFR-3 axis in cancer progression. Br $\mathrm{J}$ Cancer 96:541-545

24. Rizzato C, Scherer D, Rudnai P et al (2011) POMC and TP53 genetic variability and risk of basal cell carcinoma of skin: interaction between host and genetic factors. J Dermatol Sci 63:47-54

25. Wu X, Xin Z, Zhang W, Wu J, Chen K, Wang H, Zhu X, Pan L, Li Z, Li H, Liu Y (2013) Polymorphisms in the VEGFA promoter are associated with susceptibility to hepatocellular carcinoma by altering promoter activity. Int J Cancer 133:1085-1093

26. Yamamoto Y, Toi M, Kondo S et al (1996) Concentrations of vascular endothelial growth factor in the sera of normal controls and cancer patients. Clin Cancer Res 2:821-826

27. Yapijakis C, Koronellos N, Spyridonidou S, Vylliotis A, Avgoustidis D, Goutas N, Vlachodimitropoulos D, Vairaktaris E (2013) Association of angiotensin-converting enzyme gene insertion/deletion polymorphism with decreased risk for basal cell carcinoma. Arch Dermatol Res 305:333-339

28. Yasumatsu R, Nakashima T, Masuda M, Ito A, Kuratomi Y, Nakagawa T, Komune S (2004) Effects of the angiotensin-I converting enzyme inhibitor perindopril on tumor growth and angiogenesis in head and neck squamous cell carcinoma cells. Cancer Res Clin Oncol 130:567-573

29. Zablotna M, Sobjanek M, Nedoszytko B, Lange M, Kozicka D, Glen J, Roszkiewicz J (2013) Association of psoriasis with the VEGF gene polymorphism in the northern Polish population. J Eur Acad Dermatol Venereol 3:319-323 